\title{
Індивідуальні відмінності у формуванні техніки плавання юних спортсменів з різною силою нервової системи при застосуванні різних методів навчання
}

Юрій Близнюк
Олена Політько
Харківська державна академія фізичної культури,

Харків, Україна

Мета: дослідити вплив методик формування техніки плавання у плавців 7-8 років і вплив їх індивідуальних особливостей нервової системи на ефективність оволодіння фізичними вправами.

Матеріал і методи: дослідження проводилося протягом трьох місяців з юними плавцями (n=141), які вивчали техніку спортивних способів плавання. Попередньо вони були обстежені на предмет сили нервової системи за збудженням за трьома методиками: руховою - характер наклону кривої (ХНК), теппінг-тест, завадостійкість.

Результати: досліджено вплив різних методів початкового навчання плаванню на успішність становлення рухових умінь у дітей 7-8 років з різною силою нервової системи відносно збудження. Використовувалися репродуктивний метод, проблемне навчання та ї сполучення. Діти були поділені за силою нервової системи на групи: «сильні», «середні» та «слабкі».

Висновки: за результатами досліджень виявилося, що найбільш успішним навчання вправам було при використанні на перших 2-3-х заняттях репродуктивного методу з подальшим використанням проблемного навчання. Щодо дітей з різною силою нервової системи, то згідно з висновками багатьох дослідників середній тип за кількістю перевищує інші типи разом взяті і тому слід орієнтуватися саме на них. Якраз найбільш ефективним для дітей з середньою нервовою системою виявилося вище описане навчання.

\section{Ключові слова: сила нервової системи, методи навчання, плавання.}

\section{Вступ}

Під час навчання будь-яким руховим діям необхідно слідувати основним принципам навчання, а для більш швидкого і якісного навчання дидактика пропонує враховувати індивідуальні особливості людини [1; 3; 5; 10; 14]. Актуальність даного дослідження зумовлена необхідністю пошуку найбільш ефективних форм і методів навчання рухам, які враховували б індивідуальні особливості вищої нервової діяльності юних спортсменів-плавців, сприяли б підвищенню пізнавальної активності, самостійності й уміння творчо підходити до вирішення різних завдань не тільки в спорті, а й в інших сферах діяльності [2; 8; 10].

Об'єкт дослідження - формування рухових умінь і навичок у плавців у віці 7-8 років.

Предмет дослідження - індивідуалізація процесу формування техніки плавання з урахуванням властивостей нервової системи дітей у віці 7-8 років.

Мета дослідження - дослідити вплив методик формування техніки плавання у плавців 7-8 років і вплив їх індивідуальних особливостей нервової системи на ефективність оволодіння фізичними вправами.

\section{Завдання:}

1. Виявити особливості формування рухових умінь у плавців 7-8 років з різною силою нервової системи і вплив різних методів навчання на процес формування рухових умінь.

2. Визначити ефективність поєднання різних мето- дів навчання в процесі формування рухових умінь у юних плавців 7-8 років з різною силою нервової системи.

\section{Матеріал і методи дослідження}

Дослідження проводилося протягом трьох місяців 3 юними плавцями $(\mathrm{n}=141)$, які вивчали техніку спортивних способів плавання. Попередньо вони були обстежені на предмет сили нервової системи за збудженням за трьома методиками: руховою - характер наклону кривої (ХНК) [10; 11], теппінг-тест [6; 7], завадостійкість [12; 15]. За результатом обстеження вони були поділені на три типологічні групи: «слабкі», «середні» та «сильні». Як і в дослідженнях інших авторів [7; 10; 12], так і в нашому, ми отримали кількість "середніх», яка перевищувала «слабких» і «сильних» разом взятих.

У кожній групі опанування техніки плавання відбувалося за окремою методикою. В першій групі застосовувався репродуктивний метод [3; 5; 8], в другій - проблемний $[1 ; 4 ; 13 ; 16]$ і в третій - сполучення цих методів в різній послідовності.

На початку навчання і в кінці кожного заняття всі діти виконували контрольний тест, який вміщав в себе всі ті елементи техніки, що вивчалися на занятті. Виконання тесту супроводжувалося вимірюванням часу його виконання, кількістю рухів (частота), кількістю помилок та оцінкою за техніку методом експертної оцінки $(n=4)$ за попередньо розробленою шкалою. 


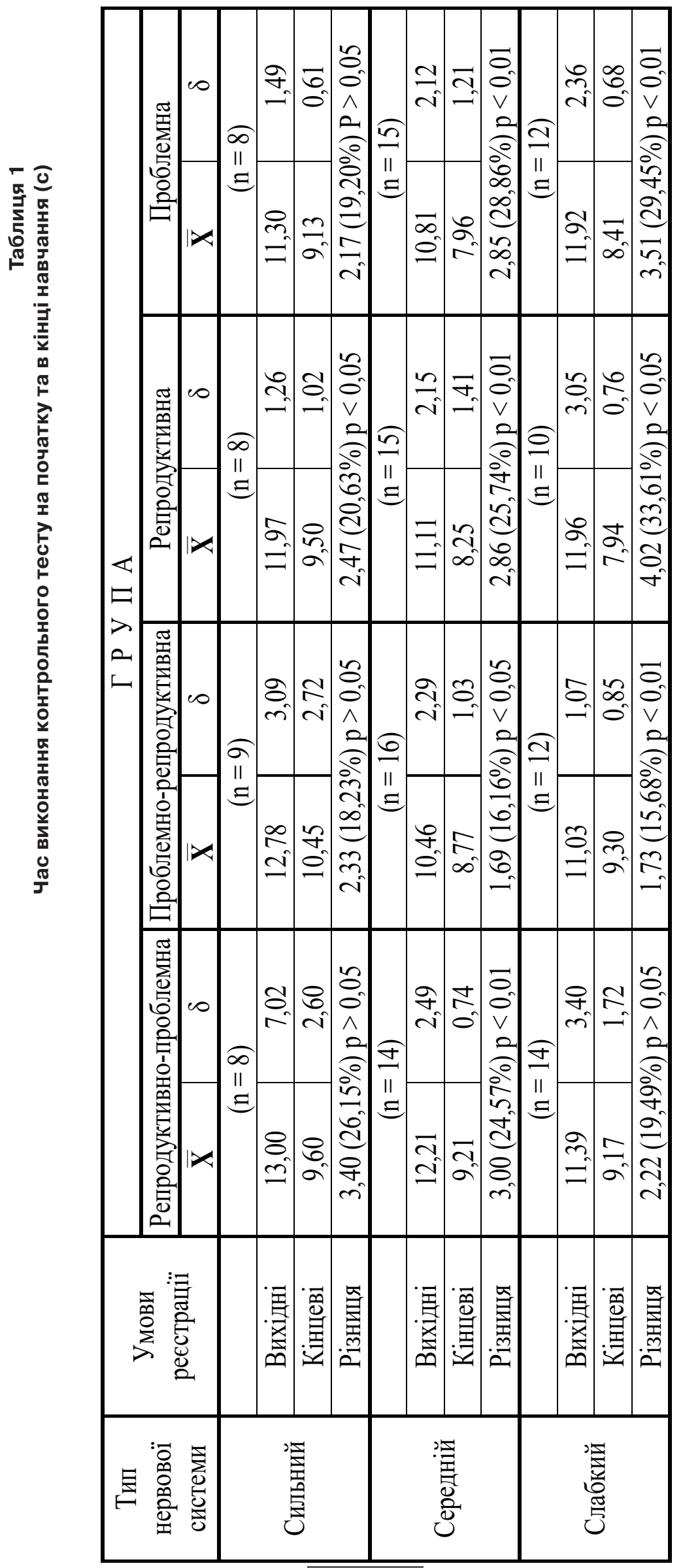




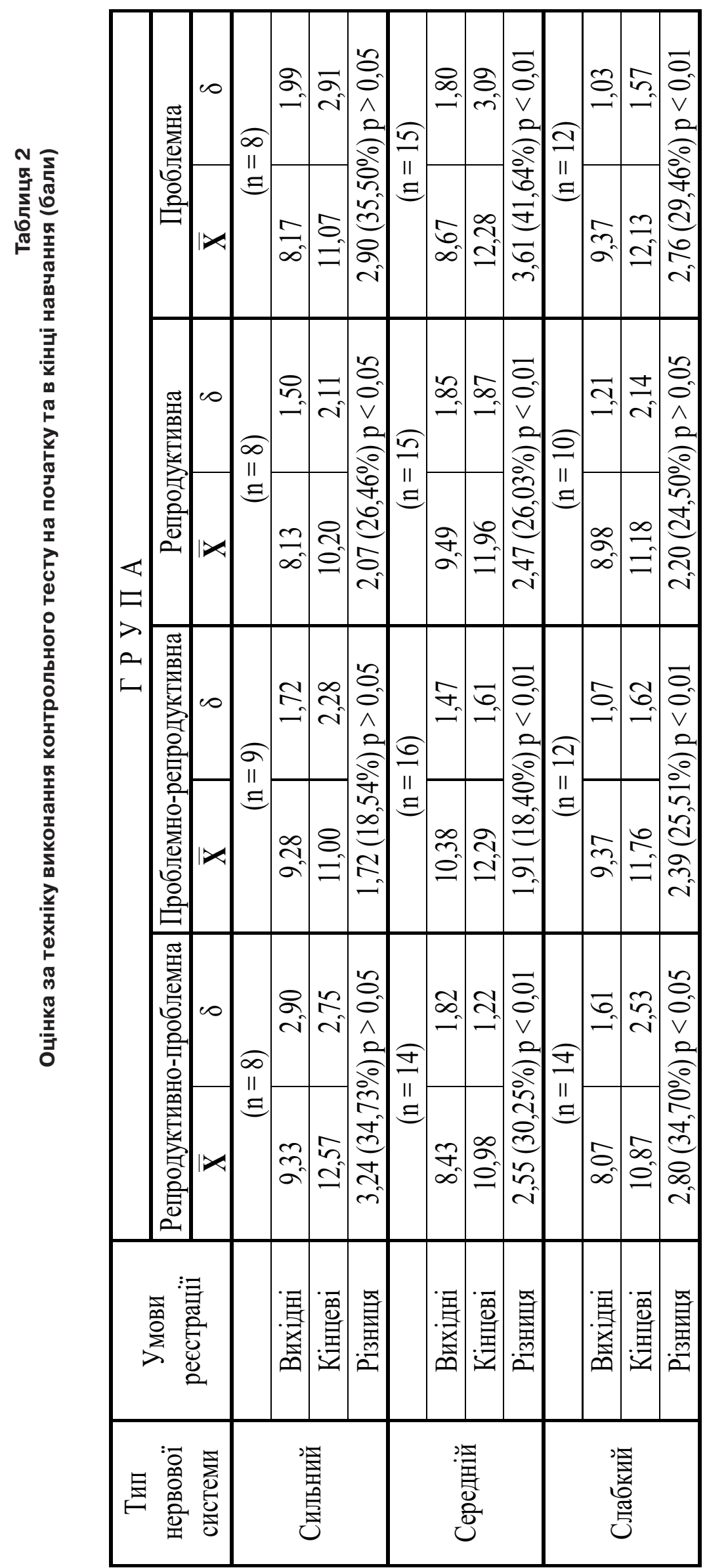




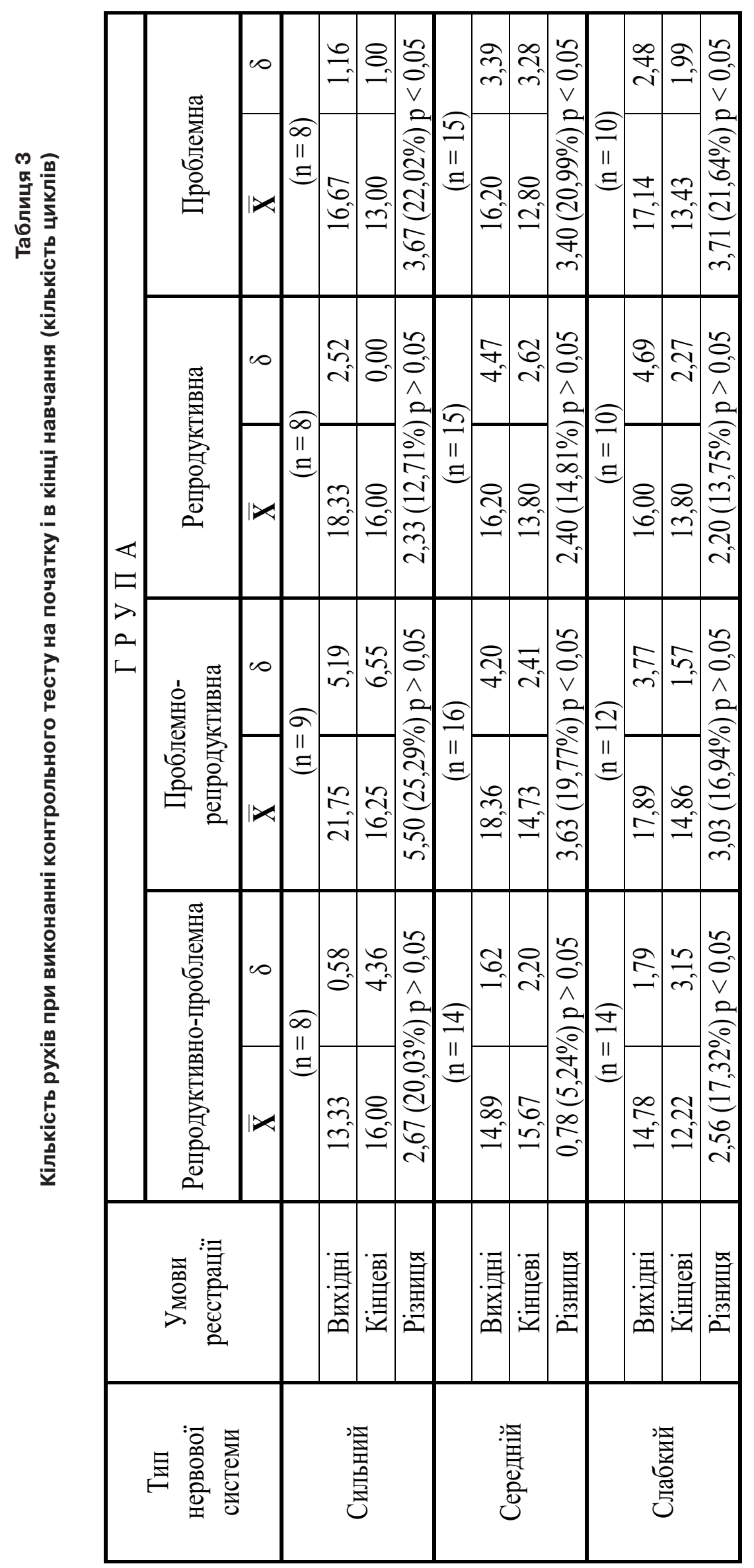




\section{Результати дослідження}

У «сильних» статистично значуще $(p<0,05)$ поліпшення часу виконання контрольного тесту відбулося тільки в «репродуктивному» класі (табл. 1), а приріст оцінки у них взагалі виявився статистично незначним у всіх групах (табл. 2). Однак, однією з причин цього явища можна вважати невелику кількість випробовуваних з сильної нервовою системою, які взяли участь в експерименті.

У представників слабкого типу значущі зміни часу відбулися у всіх групах, крім «репродуктивно-проблемної», при цьому абсолютно найкращий час $(7,94$ с) серед всіх дітей було показано на останньому занятті «слабкими» В «репродуктивній» групі.

Діти з середньою нервовою системою у всіх групах мали статистично значуще поліпшення і часу, і оцінки виконання контрольного тесту. Серед всіх дітей найвищу оцінку за техніку (12,57 с) отримали «сильні» в «репродуктивно-проблемній» групі ( $>>0,05)$, а найнижча оцінка $(10,20$ c) отримана «сильними» В «репродуктивній» групі.

Усі діти, за винятком “сильних» і «середніх» в «репродуктивно-проблемній» групі зменшили до кінця навчання кількість рухів при виконанні контрольного тесту (табл. 3). Найбільші зрушення в кількості рухів відбулися в «проблемно-репродуктивній» $\mathrm{i}$ «проблемній» групах, але в першій з них статистично значущі $(p<0,05)$ зміни відбулися лише у «середніх», а в іншій - у всіх дітей.

За весь період навчання діти сильного типу все ж не змогли домогтися значного поліпшення часу, хоча і покращували його стабільно від першого до останнього заняття. Представники середнього типу домоглися значимого $(p<0,05)$ результату на четвертому занятті і в подальшому вже не погіршували його до кінця. Випробовувані зі слабкою нервовою системою на шостому занятті, а потім і на восьмому, домоглися статистично значущого $(p<0,05)$ поліпшення часу. Наведені дані дають підставу вважати, що застосування такої методики в більшій мірі сприяє успіху в навчанні осіб середнього типу, але, в той же час, порівняно непогані результати в процесі навчання показали і представники інших типологічних груп.

Свідченням того, що ця методика надає майже однаковий вплив на успішність навчання випробовуваних 3 різною силою нервової системи може служити той факт, що в процесі проведення всіх дев'яти занять тільки на третьому була відзначена статистично значуща $(p<0,05)$ відмінність результатів між «середніми» і «слабкими», а в інших випадках значимість була відсутня.

Не сталося значного поліпшення і оцінки у випробовуваних «сильного» типу, хоча і показали вони на останньо- му занятті досить високий результат - 12,57 бала (табл. 1). Слід зауважити, що протягом перших семи занять плавці даної групи не мали суттєвих зрушень і лише на восьмому і дев'ятому заняттях дещо поліпшили $(p<0,05)$ свої результати. Таке ж становище спостерігається і в динаміці зростання оцінок у “середніх» і «слабких», які після другого-третього занять стали показувати стабільно посередні результати аж до останнього заняття.

Все ж необхідно виділити дітей зі слабкою нервовою системою, які, починаючи з другого заняття і до останнього, показували результати, що значно перевершують вихідний рівень оцінки. Поряд з тим, плавці середнього типу домоглися значного $(p<0,05)$ її поліпшення тільки на останньому занятті. Аналіз оцінок за техніку виконання контрольного тесту підкреслює, що «репродуктивнопроблемна» методика не виявила яскравої типологічно зумовленої різниці в успішності оволодіння рухами особами з різною силою нервової системи. Це підтверджується і відсутністю статистичної значущості між показниками всіх трьох груп на кожному занятті.

\section{Висновки / Дискусія}

Результати проведеного дослідження показали, що юні плавці різних типів нервової системи неоднаково сприймають навчальний матеріал, внаслідок чого формування рухових вмінь у них відбувається в різні за тривалістю часові відрізки і з властивими тільки для даної типологічної групи особливостями. Так, у сильного типу дітей формування навички протікає повільніше, ніж у інших, незалежно від методу навчання, що виражається у відставанні на 2-3 заняття за показниками часу виконання контрольного тесту і оцінки за техніку його виконання.

Сильний тип досягає найбільших успіхів при проблемному навчанні, маючи перевагу в оцінці над собі подібними в інших умовах навчання на 1,91 бала $(p<0,05)$ i в часі виконання вправи - на 0,72 c $(p<0,05)$.

Представники середнього типу однаково ефективно опановують руховими діями при використанні будь-якої з методик, але швидше домагаються значного поліпшення показників при репродуктивному і репродуктивно-проблемному навчанні.

Особи слабкого типу в 80\% випадків швидше опановують рухові дії при використанні в навчанні репродуктивного методу і в більшій мірі, ніж інші, негативно реагують на будь-які різкі зміни умов навчального процесу.

Перспектива подальших досліджень полягає у дослідженні взаємозв'язку сили нервової системи та особливостей змагальної діяльності спортсменів-плавців.

Конфлікт інтересів. Автори заявляють, що відсутній конфлікт інтересів, який може сприйматись таким, що може завдати шкоди неупередженості статті.

Джерела фінансування. Ця стаття не отримала фінансової підтримки від державної, громадської або комерційної організації.

\section{Список посилань}

1. Белкин Е. Л. (2001), «Теоретические предпосылки создания эффективных методик обучения», Начальная школа, № 4, C. $11-20$.

2. Близнюк Ю. В., Ярёменко Т. В. (2013), «Психофизиологические особенности квалифицированных пловцов, специализирующихся в способе кроль на груди», Слобожанський науково-спортивний вісник, № 3, С. 53 - 58. URL: http://nbuv.gov.ua/UJRN/ snsv_2013_3_14 
3. Боген М. М. (1989), Современные теоретико-методические основы обучения двигательным действиям: автореф. дисс. на соискание степени доктора пед. наук: спец. 13.00.04. ГЦОлИФК. М., 52 с.

4. Брызгалова С. И. (1998), Проблемное обучение в начальной школе: учебное пособие. Изд. 2-е испр. и доп. Калининград, $91 \mathrm{c}$.

5. Булгакова Н. Ж. (2017), Плавание. Водные виды спорта. М.: Инфра-М., 290 с.

6. Ильин Е.П. (2012), Психология спорта. СПб: Питер, 352 с.

7. Ильин Е. П. (2003), Психомоторная организация человека. СПб. : Питер, 384 с.

8. Методика преподавания физической культуры: 1-4 кл. (2003), под ред. Л. Д. Глазырина., Т. А. Лопатик. : метод. пособие и программа. М. : Владос, 208 с.

9. Митчик О. П. (2002), Индивидуализация физического воспитания подростков в общеобразовательной школе: автореф. дисс. на соискание учён. степени канд. наук по физ. воспит. и спорту: спец. 24.00.02. Л., 19 с.

10. Небылицын В. Д. (1990), Избранные психологические труды / под ред. Б. Ф. Ломова ; [сост. и авт. коммент. Т. Ф. Базылевич ; авт. очерка о В. Д. Небылицыне Т. Ф. Базылевич, Б. Ф. Ломов] ; Акад. пед. наук СССР. М. : Педагогика, 403 с.

11. Пейсахов Н. М. (1974), Саморегуляция и типологические свойства нервной системы. Казань, 258 с.

12. П Пиххфизиология (2004): учебник для вузов/ под ред. Ю.И. Александрова. 3-е изд., перераб. и доп., 464 с.

13. Соловьева О. В. (2003), Теоретико-экспериментальное изучение развития познавательных способностей школьников: дисс. на соискание учён. степени доктора психол. наук: спец. 19.00.01. Ставрополь, 410 с.

14. Теорія і методика фізичного виховання. Методика фізичного виховання різних груп населення (2012): підручник / під. заг. ред. Т.Ю. Круцевич. К.: Олімпійська література, Т. 2. 368 с.

15. Таймазов В. А., Голуб Я. В. (2004), Психофизиологическое состояние спортсмена (Методы оценки и коррекции). СПб.: Издательство Олимп СПб, 400 с.

16. Чащевая А. Г. (2003), Методика формирования познавательной активности учащихся младших классов на уроках физической культуры: дисс. на соискание уч. степени канд. пед наук: спец. 13.00.04 Теория и методика физического воспитания, спортивной тренировки, оздоровительной и адаптивной физической културы. Омск, 218 с.

Стаття надійшла до редакції: 06.08.2021 p.

Опубліковано: $31.08 .2021 \mathrm{p}$.

\begin{abstract}
Аннотация. Юрий Близнюк, Елена Политько. Индивидуальные различия в формировании техники плавания юных спортсменов с разной силой нервной системы при использовании различных методов обучения. Цель: исследовать влияние методик формирования техники плавания у пловцов 7-8 лет и влияние их индивидуальных особенностей нервной системы на эффективность овладения физическими упражнениями. Материал и методы: исследование проводилось в течение трех месяцев с юными пловцами $(n=141)$, которые изучали технику спортивных способов плавания. Предварительно они были обследованы на предмет силы нервной системы по возбуждению по трем методикам: двигательной - характер наклона кривой (ХНК), теппинг-тест, помехоустойчивость. Результаты: исследовано влияние различных методов начального обучения плаванию на успешность становления двигательных умений у детей 7-8 лет с разной силой нервной системы относительно возбуждения. Использовались репродуктивный метод, проблемное обучение и их сочетания. Дети были разделены по силе нервной системы на группы: «сильные», «средние» и «слабые». Выводы: по результатам исследований оказалось, что наиболее успешным обучение упражнениям было при использовании на первых 2-3-х занятиях репродуктивного метода с последующим использованием проблемного обучения. В отношении детей с разной силой нервной системы, то согласно выводам многих исследователей, средний тип по количеству превышает другие типы вместе взятые и поэтому следует ориентироваться именно на них. Как раз наиболее эффективным для детей со средней нервной системой оказалось выше описанное обучение.

Ключевые слова: сила нервной системы, методы обучения, плавание.
\end{abstract}

Abstract. Yuriy Bliznyuk, Elena Politko. Individual differences in the formation of swimming technique of young athletes with different strength of the nervous system under the conditions of applying different teaching methods. Purpose: to study the influence of methods of formation of swimming technique among 7-8 year old swimmers and the influence of their individual characteristics of the nervous system on the effectiveness of mastering physical exercises. Material and methods: The study was conducted over three months with young swimmers $(n=141)$ who studied sports swimming techniques. They were preliminarily examined for the strength of the nervous system for excitation by three methods: physical activity - the slope type of the curve, tapping test, noise immunity. Results: the influence of various methods of initial teaching in swimming on the success of the formation of motor skills in children of 7-8 years old with different strength of the nervous system relative to excitement was studied. The reproductive method, problem learning and their combinations were used. The children were divided according to the strength of the nervous system into groups: "strong", "average» and "weak». Conclusions: according to the research results, it turned out that the most successful exercise training was when using the reproductive method in the first 2-3 lessons, followed by the use of problem learning. In relation to children with different strengths of the nervous system, then, according to the conclusions of many researchers, the average type in number exceeds other types combined and therefore one should focus on them. The training described above turned out to be the most effective for children with an average nervous system.

Keywords: strength of the nervous system, teaching methods, swimming. 


\section{References}

1. Belkin, Ye. L. (2001), «Theoretical preconditions for the creation of effective teaching methods», Nachal'naya shkola, № 4, pp. 11 - 20. (in Russ.).

2. Blyznyuk, YU. V., Yarлmenko, T. V. (2013), «Psychophysiological features of skilled swimmers specializing in the method of crawling on the chest», Slobozhans'kyy naukovo-sportyvnyy visnyk, № 3, pp. 53 - 58. URL: http://nbuv.gov.ua/UJRN/snsv_2013_3_14 (in Russ.).

3. Bogen, M. M. (1989), Sovremennyye teoretiko-metodicheskiye osnovy obucheniya dvigatel'nym deystviyam [Modern theoretical and methodological foundations of teaching motor actions]: avtoref. diss. na soiskaniye stepeni doktora ped. nauk: spets. 13.00 .04 . GTSOLIFK. M., 52 p. (in Russ.).

4. Bryzgalova, S. I. (1998), Problemnoye obucheniye v nachal'noy shkole [Problematic learning in primary school]: uchebnoye posobiye. Izd. 2-ye ispr. i dop. Kaliningrad, 91 p. (in Russ.).

5. Bulgakova, N. ZH. (2017), Plavaniye. Vodnyye vidy sporta [Swimming. Water sports.]. M.: Infra-M., 290 p. (in Russ.).

6. Il'in, Ye.P. (2012), Psikhologiya sporta [Psychology of Sports]. SPb: Piter, 352 p. (in Russ.).

7. Il'in, Ye. P. (2003), Psikhomotornaya organizatsiya cheloveka [Psychomotor organization of a person]. SPb. : Piter, 384 p. (in Russ.).

8. Metodika prepodavaniya fizicheskoy kul'tury: 1-4 kl. [Physical culture teaching methodology: 1-4 grades] (2003), pod red. L. D. Glazyrina., T. A. Lopatik. : metod. posobiye i programma. M. : Vlados, 208 p. (in Russ.).

9. Mitchik, O. P. (2002), Individualizatsiya fizicheskogo vospitaniya podrostkov v obshcheobrazovatel'noy shkole [Individualization of physical education of adolescents in a comprehensive school]: avtoref. diss. na soiskaniye uchon. stepeni kand. nauk po fiz. vospit. i sportu: spets. 24.00.02. L., 19 p. (in Russ.).

10. Nebylitsyn, V. D. (1990), Izbrannyye psikhologicheskiye trudy [Selected psychological works]/ pod red. B. F. Lomova; [sost. i avt. komment. T. F. Bazylevich ; avt. ocherka o V. D. Nebylitsyne T. F. Bazylevich, B. F. Lomov] ; Akad. ped. nauk SSSR. M. : Pedagogika, 403 p. (in Russ.).

11. Peysakhov, N. M. (1974), Samoregulyatsiya i tipologicheskiye svoystva nervnoy sistemy [Self-regulation and typological properties of the nervous system]. Kazan', 258 p. (in Russ.).

12. Psikhofiziologiya [Psychophysiology] (2004): uchebnik dlya vuzov/ pod red. YU.I. Aleksandrova. 3-ye izd., pererab. i dop., 464 p. (in Russ.).

13. Solov'yeva, O. V. (2003), Teoretiko-eksperimental'noye izucheniye razvitiya poznavatel'nykh sposobnostey shkol'nikov [Theoretical and experimental study of the development of cognitive abilities of schoolchildren]: diss. na soiskaniye uchon. stepeni doktora psikhol. nauk: spets. 19.00.01. Stavropol', 410 p. (in Russ.).

14. Teoriya i metodyka fizychnoho vykhovannya. Metodyka fizychnoho vykhovannya riznykh hrup naselennya [Theory and methods of physical education. Methods of physical education of different groups of the population] (2012): pidruchnyk / pid. zah. red. T.YU. Krutsevych. K.: Olimpiys'ka literatura, T. 2. 368 p. (in Russ.).

15. Taymazov, V. A., Golub, YA. V. (2004), Psikhofiziologicheskoye sostoyaniye sportsmena (Metody otsenki i korrektsii) [Psychophysiological state of an athlete (Methods of assessment and correction)]. SPb.: Izdatel'stvo Olimp SPb, 400 p. (in Russ.).

16. Chashchevaya, A. G. (2003), Metodika formirovaniya poznavatel'noy aktivnosti uchashchikhsya mladshikh klassov na urokakh fizicheskoy kul'tury [Methodology for the formation of cognitive activity of primary school students in physical culture lessons: diss. to apply for an account]: diss. na soiskaniye uch. stepeni kand. ped nauk: spets. 13.00.04 Teoriya i metodika fizicheskogo vospitaniya, sportivnoy trenirovki, ozdorovitel'noy i adaptivnoy fizicheskoy kultury. Omsk, 218 p. (in Russ.).

Received: 06.08.2021.

Published: 31.08 .2021$.

\section{Відомості про авторів / Information about the Authors}

Близнюк Юрій Володимирович: доцент кафедри водних видів спорту; Харківська державна академія фізичної культури: вул.. Клочківська 99, м. Харків, 61058, Україна.

Близнюк Юрий Владимирович: доцент кафедры водных видов спорта; Харьковская государственная академия физической культуры: ул .. Клочковская 99, г.. Харьков, 61058, Украина.

Yuriy Bliznyuk: Associate Professor of the Department of Water Sports; Kharkiv State Academy of Physical Culture: 99 Klochkivska Street, Kharkiv, 61058, Ukraine.

ORCID: https://orcid.org/0000-0003-1661-5344

E-mail: jurane@ukr.net

Політько Олена Валеріївна: к. фіз.вих., доцент; Харківська державна академія фізичної культури: вул.. Клочківська 99, м. Харків, 61058, Україна.

Политько Елена Валерьевна: к.физ.вих., доцент; Харьковская государственная академия физической культуры: ул. Клочковская 99, г. Харьков, 61058, Украина.

Elena Politko: PhD (Physical Education and Sport), Associate Professor; Kharkiv State Academy of Physical Culture: 99 Klochkivska Street, Kharkiv, 61058, Ukraine.

ORCID: http://orcid.org/0000-0001-6481-196X

E-mail: elena.politko@gmail.com 